\title{
Development and Validation of the Self-Esteem Scale of Toulouse (ETES) in Vietnam
}

\author{
Trinh Thi Linh*, Tran Thu Huong, Ngo Mai Trang \\ Faculty of Psychology, University of Social Sciences and Humanities, Vietnam National University (VNU-Hanoi), \\ Hanoi, Vietnam \\ Email: *anhlinh_huong@yahoo.com, tth.ussh@gmail.com, maitrang_ngo@yahoo.com
}

How to cite this paper: Linh, T.T., Huong, T.T. and Trang, N.M. (2017) Development and Validation of the Self-Esteem Scale of Toulouse (ETES) in Vietnam. Open Journal of Social Sciences, 5, 114-125.

http://dx.doi.org/10.4236/jss.2017.51010

Received: December 16, 2016

Accepted: January 13, 2017

Published: January 16, 2017

Copyright $\odot 2017$ by authors and Scientific Research Publishing Inc. This work is licensed under the Creative Commons Attribution International License (CC BY 4.0).

http://creativecommons.org/licenses/by/4.0/ (c)

\begin{abstract}
Self-esteem is no longer a new concept in the field of psychology in the whole world in general as well as in Vietnam in particular. There is a rich diversity of self-esteem measurement tools that have been devised and developed. However, in Vietnam, most of the researchers only use the original measurement tools without adapting them to the cultural-social context of Vietnam. Hence, this research aims to evaluate the construction and reliability of an existing popular measurement tool of self-esteem in Europe-which is ETES-in the context of Vietnamese culture. An empirical study was conducted in Vietnam and 1505 valid responses of adolescents were collected. Five sub-scaleswhich are physical self, emotional self, academic-future self, social self and familial self-were identified through an exploratory factor analysis. The last dimension (familial self) is considered a typical self-esteem area of Vietnamese adolescents. The test-retest reliability demonstrates strong reproducibility of the self-esteem scale and subscales. This new tool is useful for examining how often adolescents in Vietnam evaluate their self-esteem.
\end{abstract}

\section{Keywords}

Self-Esteem, The Self-Esteem Scale of Toulouse (ETES), Adolescent, Vietnam

\section{Introduction}

The development of the young is one of any countries' most compelling concerns. Furthermore, Vietnam is a developing country and the adolescents in this country-like in any other developing ones-must face up to numerous trials directly linked to the significant changes that the economic and social climate are going through. Confronting with new risks, these adolescents are vulnerable. The percentage of adolescents violating laws or having abortions has increased. 
Particularly, according to the Ministry of Health $(\mathrm{MOH})$, the number of teenagers having abortions is approximately one fifth of all abortions nationwide each year. Recent reports from hospitals in Hanoi and Ho Chi Minh City cite a significant increase in the number of adolescent abortions (cited according to [1]). Understanding the psychological aspect of adolescents has become more important and necessary than ever. The area of self-esteem is therefore a rapidly expanded research topic in the field of social science in Vietnam, especially in psychology.

An overview of previous research on self-esteem shows that a lot of measurement tools have been used on the sample group of Vietnamese such as the Toulouse Self-Esteem Scale [2], the Coopersmith Self-Esteem Inventory [3], the Culture-Free Self-Esteem (Battle, 1981, cited according to [4]), the Rosenberg scale [5], the Harter scale [6], etc. These tools have been translated into Vietnamese and used increasingly in the practice of psychology in Vietnam. But Markus and Kitayama [7] have pointed out that some aspects of the self may be different according to which culture is referred and that the content and structure of the self may differ markedly by culture. Hence, the fact that the tool may be culture-based somehow explains the reason why there is a great demand for the development of a self-esteem measurement tool for the Vietnamese.

\section{Self-Esteem and Measurement}

Self-esteem has always been considered one of the most basic needs of each individual. According to Maslow [8]: "All people in our society (with a few pathological exceptions) have a need or desire for a stable, firmly based, (usually) high evaluation of themselves, for self-respect, or self-esteem, and for the esteem of others. [...]. Satisfaction of the self-esteem need leads to feelings of self-confidence, worth, strength, capability and adequacy of being useful and necessary in the world. But thwarting of these needs produces feelings of inferiority, of weakness and of helplessness".

The notion of self-esteem is not new. This term was first coined by James in 1890. Besides being one of the oldest concepts in psychology, self-esteem is also the third most frequently occurring theme in psychological literature [9]. Given such a long and varied history, it is not surprising to find that many theories have their own perspective on self-esteem.

The unidimensional model proposed that self-esteem is an overall construct, referring to the most general self-evaluation. Pioneering research supporting this approach was conducted by Coopersmith [3], Piers \& Harris [10], Rosenberg [5]. In support of the unidimentional model, Rosenberg [5] suggested that selfesteem reflected positive or negative attitudes toward oneself. Therefore, Rosenberg pointed out that self-esteem consists of two different connotations: one for people who consider themselves "very good", which means they have higher self-esteem than others, and one for those who think they are just "good enough". Based on this theoretical approach, Rosenberg has proposed a 10-item self-esteem scale (Rosenberg Self-Esteem Scale), including 5 positive items and 5 
negative items. The scale gives a score depicting the participant's level of selfesteem.

The unidimentional model has been proved to have many limitations because in order to confirm one's existence, each individual must take part in various activities in social life generally and vocational activities specifically. Therefore, Harter has criticized this model. She suggested that the multidimentional model should be used when examining self-esteem. Combining his ideas in 1965s and Harter's point of view, Rosenberg [11] made some changes in his way of approaching self-esteem. With the outcomes of a research on 1886 high school students (grade 10), Rosenberg and his colleagues have reported a relation between overall self-esteem and self-esteem in particular areas of each person (e.g. in the area of studying with academic self). They pointed out that self- esteem in specific area is more suitable for behavioral aspects, whilst overall self-esteem would serve better in the aspect of an individual's mental health. Therefore, for these authors, self-esteem has become both unidimensional and multidimentional.

When it comes to the multidimensional theory of self-esteem, it is necessary to mention research conducted by Marsh and colleagues [12] [13]. Based on studies of Shavelson and et al. [14], Marsh and colleagues have devised self-esteem questionnaire (Self Description Questionnaire-SDQ) with three versions-I, II, III for different groups of subjects with ages ranging from primary students to adolescents. Also during this period of time, Harter's work was highly regarded by those who were interested in self-esteem. Stemming from James' viewpoint [15] when suggesting that self-esteem of an individual is reinforced in successful situations, and Cooley's ideas (1902) as he pointed out that self-esteem is developed according to the way we encode the reaction of others to us, Harter (1985, cited according to [16]) proposed a self-esteem scale for children (Self-Perception Profile for Children-S.P.P.C) and 3 years later, in 1988, she came up with another self-esteem scale for adolescents (Self-Perception Profile for Adolescents -S.P.P.A) on the basis of S.P.P.C. In the latter one, Harte added 3 typical aspects of adolescents, which are close relationship with friends, attractiveness in romantic relationship and capabilities in their work. After carrying out research, Harter came to conclusion that negative self-esteem of a child in a special domain did not necessarily affect the overall satisfaction of their personal values.

Based on theoretical overview of previously conducted research by Coopersmith [3], Rosenberg [5], Harter [17] [18], Oubrayrie et al. [2] devised an attitude scale to measure self-esteem of targeted subjects in the most general way as well as on specific aspects, and they named it The self-esteem scale of Toulouse (Échelle Toulousaine d'Estime de soi-ETES), which will be presented in more details in the following part of this paper.

In summary, each author with their own opinions and a specific culturalsocial environment in which they lived has contributed a rich diversity of viewpoints to different fields of self-esteem. Even though there were no complete compatibilities among these fields, generally we can affirm that these fields are 
only relative in nature because the simulation and evaluation of each individual may vary according to different aspects. Therefore, it seems that the change of one self-esteem aspect (e.g. social ego) would not necessarily has an impact on other self-esteem aspect of that person (e.g. academic ego), and it is even harder to confirm that the change of one aspect would influence the overall self-esteem.

\section{The Self-Esteem Scale of Toulouse (ETES)}

Based on the multidimentional theory of self-esteem, ETES focuses on measuring self-esteem of an individual in five main areas: academic self, physical self, emotional self, future self and social self. These five areas were developed by how individuals perceive and accept themselves. What makes this scale special is that it emphasizes the Emotional self, which does not receive much attention in previous scales.

ETES includes 60 items with 5-option answer like Likert scale from "completely disagree" to "completely agree". These 60 items were distributed evenly to 5 areas of self-esteem mentioned above. Hence, each area contains 12 items (6 positive items and 6 negative items). Specifically:

- The Emotional self refers to the representation of the control of emotions, of impulsivity, and the self-control.

- The Social self refers to the representation that the subject has of his interactions with others (parents, friends, schoolmates).

- The Academic self corresponds to the representation of the skills, performances and behaviors of the subject in his school setting.

- The Physical self refers to the representation that the subject has of his capacities, and his bodily image.

- The Future self corresponds to representations that the subject has of his future, and of his future roles of adult.

In general, these aspects are closely related to adolescents' life in every community because they are connected to the biological and psychological features of this group. The assessment areas are not too fragmented and do not delve too much into emotional life of adolescents. Hence, we decided to adapt ETES for researching in Vietnam.

\section{General Method}

\subsection{Sampling}

According to survey data of GSO [19], in 2009, the adolescent population aged $10-19$ made up $18.7 \%$ ( 16 million) of the total population ( $10-14$ years $=8.5 \%$ and $15-19$ years $=10.2 \%)$. Based on these statistics of adolescents, this research was conducted on a sample group of 1505 adolescents who are currently studying in secondary and high school in all three regions of Vietnam: Hanoi (representing the North), Hue (representing the Central of Vietnam) and Ho Chi Minh City (representing the South). We believe this number of subjects could guarantee the margin of error allowed in order to produce the most general 
conclusions about self-esteem of Vietnamese adolescents.

\subsection{Process}

In the process of data collection, all participants of this study were randomly selected, regardless of academic ability and background. Questionnaires were completed on a voluntary basis, without any strings attached. During this process, all questions of participants were answered immediately to ensure truthfulness and objectivity of all the information obtained.

\subsection{Material}

Based on the research of Dang Hoang Minh [4], Trinh Thi Linh [20] [21], we realize the importance of self-esteem of Vietnamese adolescents in the aspect of familial self. So besides five aspects of self-esteem that were proposed by ETES, we decided to keep the familial aspect of self-esteem. However, based on the results of previously conducted research, we rebuilt the familial sub-scale to measure how children perceive and evaluate the role and importance of family relationships as well as how they feel within these relationships in the most general way. Similar to other sub-scale in ETES, familial sub-scale contains 12 items with answers designed in Likert 5-point scale from "completely disagree" to "completely agree". In this sub-scale, three items were taken from the self-esteem scale of Coopersmith [3] ("In my family, no one pays attention to what I say, how I think", "in my family, no one cares about me", "I usually feel left out in my family"); one item was taken from scale of Marsh [12] and Fitts [22] ("My family love me"). Other items were developed by authors on the basis of previous research. Therefore, the initial scale that we wish to adapt to the sample group of Vietnamese adolescents includes 72 items covering 6 areas: familial, social, academic, future, physical and emotional.

\subsection{Method of Translation of ETES}

To guarantee that the items of ETES are most closely translated to Vietnamese, we have made translation from French to Vietnamese and vice versa by experts in French who have experience in psychology. The translation from French to Vietnamese has been made by 2 psychologists who have studied in France. The 2 translation versions have then been compared to guarantee the closest translation of the terms. We have tried to use the terms that are most appropriate with the teenagers. The terms are guaranteed to be common, popular and easy to understand for teenagers in all North, Center and South of Vietnam.

After being translated, the Vietnamese version of ETES, named EVES (Échelle Vietnamienned'Estime de Soi), has been checked and reviewed the perspicuity by our colleagues working in psychology area.

The translation from Vietnamese to French has been executed by the Master graduates of the Faculty of Psychology. Inevitably the terms are checked and reviewed after translation. The French version of EVES has then been reviewed the compatibility with the original version by the person who made ETES. 
The final EVES is the combination of the versions made in those translations.

\section{Study 1}

The pilot study on sample group of 432 participants, who are currently enrolling in secondary schools and high schools in Hanoi and Hue with age ranging from 14 to 18 , showed that the scale has high reliability with Cronbach's Alpha = 0.87. Based on the value of Crobach's Alpha if item deleted as well as the value $r$ of Corrected Item-total correlation, we have removed all items with $\alpha>0.87$ and $r \leq 0.1$. The final scale includes 62 items that meet the statistical demand.

A principal component factor analysis revealed five factors with eigenvalues greater than 1.00 . These factors accounted for $49.2 \%$ of the overall variability in scores. There are $167(28.0 \%)$ nonredundant residuals with absolute values greater than 0.05.The Kaiser-Meyer-Olkin Measure (KMO) is 0.88, the value of Bartlett's Test of Sphericity is 0.000 , the Measure of Sampling Adequacy (MSA) values range from 0.60 to 0.95 . An examination of the item loadings revealed the five factors to be familial self, physical self, emotional self, academic-future self and social self (see Table 1 ).

Looking at the results in Table 1, it's easy to notice that the contents of all obtained items are consistent with factors to which they belong. Only item "I am proud of my learning outcomes" fell into factor "physical self" with lowest factor loading coefficient $(0.447)$. Does it indicate that children perceive a certain relation between "learning outcomes" with their appearance or is it because the number of participants may not be large enough to produce more objective results? Within the scope of this initial study, it's hard to draw any conclusions. Therefore, we decided to keep all these 33 obtained items to conduct the second study.

\section{Study 2}

This study was carried out on 1505 Vietnamese adolescent living in all 3 regions of Vietnam: North, Central and South.

Using the 33-item scale obtained from Study 1, we tested the reliability of this scale on the sample group mentioned above. The results confirmed high reliability of the scale with Cronbach's Alpha $=0.86$, Cronbach's Alpha if item deleted range from 0.847 to 0.857 , Corrected item-Total correlation range from 0.17 to 0.53 . Factor analysis (with orthogonal rotation-varimax) was also used to examine the stability of factors obtained from Study 1 with the results as followed:

The value of Kaiser-Meyer-Olkin Measure is 0.9, the Bartlett's Test of Sphericity is 0.000 , the Measure of Sampling Adequacy (MSA) range from 0.77 to 0.95 . There are $156(29.0 \%)$ nonredundant residuals with absolute values greater than 0.05 .

The data in Table 2 illustrate that factor analysis produced a virtual compatibility with the results we received in Study 1. The Cronbach's Alpha coefficients are acceptable for all factors obtained. The only difference from Study 1 is that in this study, we noted a change of item "I am proud of my learning outcomes". In Study 1, this item belonged to "Physical self" factor, but in Study 2, it fell into the group of "Academic-Future self" factor with factor loading $=0.486$. In terms of literal logic, this change is entirely rational. It ensures consensus for all items in explaining obtained factors. 
T. T. Linh et al.

Table 1. Summary of exploratory factor analysis results of the SPSS EVES scale $(\mathrm{N}=432)$.

\begin{tabular}{|c|c|c|c|c|c|c|}
\hline \multirow[b]{2}{*}{ Item } & \multicolumn{5}{|c|}{ Rotated factor loadings } & \multirow{2}{*}{$\mathrm{r}$} \\
\hline & Family self & Physical self & Emotional self & Academic-Future self & Social self & \\
\hline I easily feel satisfied with my face and body & & 0.630 & & & & 0.35 \\
\hline I feel good about myself & & 0.613 & & & & 0.37 \\
\hline I notice that I am usually angry and tense & & & 0.528 & & & 0.35 \\
\hline I am proud of my body & & 0.763 & & & & 0.39 \\
\hline I often feel worried & & & 0.580 & & & 0.33 \\
\hline I think I have a well-proportion body & & 0.553 & & & & 0.33 \\
\hline In general, I am confident about myself & & 0.549 & & & & 0.41 \\
\hline I understand the lesson in class very quickly & & & & 0.644 & & 0.35 \\
\hline In class, I like to receive questions from teachers & & & & 0.680 & & 0.18 \\
\hline I easily feel let down if my learning outcomes are not good & & & 0.502 & & & 0.21 \\
\hline I am satisfied with myself & & 0.688 & & & & 0.45 \\
\hline People feel bored when I am in their groups & & & & & 0.665 & 0.32 \\
\hline I remember what I learn easily & & & & 0.612 & & 0.36 \\
\hline I believe in my future & & & & 0.484 & & 0.39 \\
\hline In class, people always like to be with me & & & & & 0.662 & 0.28 \\
\hline I have a feeling that I can't do many things as well as others & & & 0.495 & & & 0.26 \\
\hline Other people seem to listen and do what I say & & & & & 0.529 & 0.12 \\
\hline I feel scared and cry when people criticize me & & & 0.602 & & & 0.26 \\
\hline I am satisfied with the development of my body & & 0.655 & & & & 0.39 \\
\hline I feel lost in groups & & & & & 0.533 & 0.44 \\
\hline I am proud of my learning outcomes & & 0.447 & & & & 0.39 \\
\hline I am pleased to be a member of my family & 0.700 & & & & & 0.53 \\
\hline I wish I had been born in another family & 0.676 & & & & & 0.50 \\
\hline My family think of me as if I was nothing & 0.694 & & & & & 0.44 \\
\hline I am proud to be my parents' child & 0.762 & & & & & 0.52 \\
\hline My family love me & 0.797 & & & & & 0.56 \\
\hline I wish I can live with my parents forever & 0.464 & & & & & 0.26 \\
\hline In my family, people don't pay attention to what I say & 0.701 & & & & & 0.53 \\
\hline In my family, no one cares about me & 0.732 & & & & & 0.50 \\
\hline I believe my family would have been better without me & 0.681 & & & & & 0.53 \\
\hline My family are proud of me & 0.583 & & & & & 0.58 \\
\hline My parents respect me & 0.741 & & & & & 0.58 \\
\hline I usually feel left out in my family & 0.756 & & & & & 0.59 \\
\hline Eigenvalues & 7.58 & 3.24 & 2.09 & 1.73 & 1.45 & \\
\hline$\%$ of variance & 21.65 & 9.25 & 5.98 & 4.95 & 4.15 & \\
\hline$\alpha$ & 0.90 & 0.79 & 0.61 & 0.62 & 0.57 & \\
\hline $\begin{array}{l}\text { Extraction Method: Principal Component Analysis. } \\
\text { Rotation Method: Varimax with Kaiser Normalization. }\end{array}$ & & & & & & \\
\hline
\end{tabular}


Table 2. Summary of exploratory factor analysis results of the SPSS EVES scale $(\mathrm{N}=1505)$.

\begin{tabular}{|c|c|c|c|c|c|}
\hline \multirow[b]{2}{*}{ Item } & \multicolumn{5}{|c|}{ Rotated factor loadings } \\
\hline & Family self & Physical self & Emotional self & Academic-Future self & Social self \\
\hline I easily feel satisfied with my face and body & & 0.656 & & & \\
\hline I feel good about myself & & 0.657 & & & \\
\hline I notice that I am usually angry and tense & & & 0.583 & & \\
\hline I am proud of my body & & 0.700 & & & \\
\hline I often feel worried & & & 0.645 & & \\
\hline I think I have a well-proportion body & & 0.592 & & & \\
\hline In general, I am confident about myself & & 0.605 & & & \\
\hline I understand the lesson in class very quickly & & & & 0.708 & \\
\hline In class, I like to receive questions from teachers & & & & 0.545 & \\
\hline I easily feel let down if my learning outcomes are not good & & & 0.532 & & \\
\hline I am satisfied with myself & & 0.647 & & & \\
\hline People feel bored when I am in their groups & & & & & 0.684 \\
\hline I remember what I learn easily & & & & 0.680 & \\
\hline I believe in my future & & & & 0.518 & \\
\hline In class, people always like to be with me & & & & & 0.662 \\
\hline I have a feeling that I can't do many things as well as others & & & 0.521 & & \\
\hline Other people seem to listen and do what I say & & & & & 0.469 \\
\hline I feel scared and cry when people criticize me & & & 0.521 & & \\
\hline I am satisfied with the development of my body & & 0.649 & & & \\
\hline I feel lost in groups & & & & & 0.603 \\
\hline I am proud of my learning outcomes & & & & 0.486 & \\
\hline I am pleased to be a member of my family & 0.695 & & & & \\
\hline I wish I had been born in another family & 0.671 & & & & \\
\hline My family think of me as if I was nothing & 0.636 & & & & \\
\hline I am proud to be my parents' child & 0.742 & & & & \\
\hline My family love me & 0.787 & & & & \\
\hline I wish I can live with my parents forever & 0.571 & & & & \\
\hline In my family, people don't pay attention to what I say & 0.613 & & & & \\
\hline In my family, no one cares about me & 0.715 & & & & \\
\hline I believe my family would have been better without me & 0.646 & & & & \\
\hline My family are proud of me & 0.522 & & & & \\
\hline My parents respect me & 0.673 & & & & \\
\hline I usually feel left out in my family & 0.679 & & & & \\
\hline Eigenvalues & 6.72 & 3.26 & 2.22 & 1.57 & 1.38 \\
\hline$\%$ of variance & 20.27 & 9.88 & 6.74 & 4.75 & 4.19 \\
\hline$\alpha$ & 0.89 & 0.79 & 0.59 & 0.64 & 0.55 \\
\hline
\end{tabular}




\section{Study 3: Test-retest reliability}

The results of the test-retest reliability assessment on 94 Vietnamese adolescents demonstrated strong reproducibility of the self-esteem scale and subscales (Intraclass correlation (95\% CI): overall scale, ICC $=0.91(0.84,0.95), \mathrm{p}<0.001$; familial self, ICC $=0.92(0.86,0.95), \mathrm{p}<0.001$; physical self, ICC $=0.90(0.84$, $0.94), \mathrm{p}<0.001$; academic-future self, ICC $=0.87(0.82,0.90)$; social self, ICC $=$ $0.88(0.84,0.89)$; emotional self, ICC $=0.90(0.86,0.92)$ (see Table 3$)$.

\section{Discussions}

\subsection{The Importance of Familial Self}

A noticeable thing that we recorded over 2 studies was the importance of Familial self in self-esteem of Vietnamese adolescents. The results of factor analysis obtained in both studies confirm the existence of 12 items with scientific data that are statistically significant. We believe this could be explained based on the cultural-social reality in Vietnam. Accordingly, even though there have been major changes in Vietnam society, family have always played an important role in the process of formation and development of Vietnamese adolescents' personalities. Especially, in Eastern countries such as Vietnam, where people value sense over sensibility, family has such strong influences on each individual's perception of themselves as a family member. The life philosophies "blood is thicker than water" (một giọt máu đào hơn ao nước lã), "brothers and sisters are as close as hands and feet" (anh em như thể tay chân) (Vietnamese proverb)... have imprinted into the sub-consciousness of Vietnamese people in general as well as teenagers in particular. Therefore, among the aspects of self-esteem of Vietnamese adolescents, the familial factor has always appeared as a stable and everlasting one.

\subsection{The Emergence of Academic-Future Self}

We believe that the combination of academic self and future self into one factor is totally understandable in cultural-social context of Vietnam. Under the influence of three major regions (Confucianism-Taoism-Buddhism), Vietnamese people have always put emphasis on education since ancient times. In fact, in some periods in the history, pursuing an education was considered the only way to success in society. Therefore, even though Vietnamese society has gone through many changes, most people still believe that their future depends on

Table 3. Test-retest reliability of the Self-esteem scale of Vietnamese adolescents $(n=94)$.

\begin{tabular}{ccc}
\hline & Intraclass correlation coefficient $(95 \% \mathrm{CI})$ & $\mathrm{p}$-value \\
\hline Family self & $0.92(0.86-0.95)$ & $<0.001$ \\
Physical self & $0.90(0.84-0.94)$ & $<0.001$ \\
Academic-Future self & $0.87(0.82-0.90)$ & $<0.001$ \\
Social self & $0.88(0.84-0.89)$ & $<0.001$ \\
Emotional self & $0.90(0.86-0.92)$ & 001 \\
\hline
\end{tabular}


their learning outcomes at schools. Good academic results lead to a good future and vice versa. Vietnamese adolescents seem to be imbued with this belief. Therefore, it is easy to explain why they perceive their future in connection with their academic ability at school.

Moreover, we believe that there is another reason that can be used to explain why future self is not an independent factor but it is closely related to the future self area of Vietnamese adolescents' self-esteem. That is the fact that there are many shortcomings in the work of vocational guidance for young people in Vietnam. Schools offer no detailed vocational guidance for students. Mass media do not provide much relevant information in this area. Hence, most of Vietnamese students do not have the habit of setting future plans. It seems like all they know is to focus on studying with a firm belief that they would get any desired job once they have a college/university degree. The consequence is that the familial self has not been recognized independently in Vietnamese adolescents' self esteem, which was pointed out by previous research [4] [20] [21].

\subsection{The Emergence of Emotional Self}

In their doctoral theses, Dang Hoang Minh [4] and Trinh Thi Linh [20] used ETES to measure self-esteem of Vietnamese adolescents but both these studies did not record the level of self-esteem of this group of subjects in the aspect of emotional self. We wondered if this was due to the fact that the number of subjects was not big enough or due to limitations of the conducting process. These assumptions give us huge concerns. According to developmental psychologists, there are important emotional changes in the period of adolescence. Understanding the level of adolescents' self-esteem in this area may allow us to understand more about children in this transitional period. Moreover, even though Vietnamese people in general and Vietnamese adolescents in particular don't have the habit of expressing emotions with others, it does not mean that the emotional self cannot be measured in these subjects. This assumption was confirmed by the results of our research. In other words, the emotional self appears to be an independent factor besides other factors that we obtain in this study. This also proves the assumption that we have made about the size of the sample group of previous research.

\section{Conclusion}

This study adapted ETES to the context of Vietnamese culture and tested the reliability and validity of this new version of ETES, which is used for Vietnamese population and named EVES. The reliability and validity indices of EVES are acceptable. From a general perspective of reliability such as IC and validity such as EFA result, EVES can be used for researching purposes in the field of psychology in Vietnam.

\section{Acknowledgements}

This research is funded by Asia Research Center, Vietnam National University, 
Hanoi (ARC-VNU).

\section{References}

[1] Center for Population Studies and Informations (2003) Adolescents and Youth in Vietnam. Hanoi.

[2] Oubrayrie, N., De Léonardis, M. and Safont, C. (1994) Un outil pour l'évaluation de l'estime de soi chez l'adolescent: l'ETES. Revue Européenne de Psychologie Appliquée, $4^{\text {ème }}$ trimestre, vol n'4, 309-317.

[3] Coopersmith, S. (1984) Inventaire d'estime de soi. Centre de Psychologie Appliquée, Paris.

[4] Minh, D.H. (2006) Orientation de soi chez les adolescents vietnamiens souffrant d'une maladie chronique: La dynamique entre l'estime de soi et la représentation de sa propre maladie. Thèse de doctorat de Psychologie Nouveau régime, Université Toulouse II.

[5] Rosenberg, M. (1965) Society and the Adolescent Self-Image. Princeton University Press, Princeton, NJ. https://doi.org/10.1515/9781400876136

[6] Harter, S. (1982) The Perceived Competence Scale for Children. Child Development, 53, 87-97. https://doi.org/10.2307/1129640

[7] Markus, H.R. and Kitayama, S. (1991) Culture and the Self: Implications for Cognition, Emotion, and Motivation. Psychological Review, 98, 224-253.

https://doi.org/10.1037/0033-295X.98.2.224

[8] Maslow, A.H. (2004) On Dominance, Self-Esteem, and Self-Actualization. Brooks/ Cole Publ., Monterey.

[9] Rodewalt, F. and Tragakis, M.W. (2003) Self-Esteem and Self-Regulation: Toward Optimal Studies of Self-Esteem. Psychological Inquiry, 14, 66-70.

[10] Piers, E.V. and Harris, D.B. (1964) Age and Other Correlates of Self-Concept in Children. Journal of Educational Psychology, 55, 91-95.

https://doi.org/10.1037/h0044453

[11] Rosenberg, M., Schooler, M., Schoenbach, C. and Rosenberg, F. (1995) Global Self-Esteem and Specific Self-Esteem. American Sociological Review, 60, 141-156. https://doi.org/10.2307/2096350

[12] Marsh, H.W. (1984) Self Description Questionnaire III: The Construct Validity of Multidimensional Self-Concept Ratings by Late Adolescents. Journal of Educational Measurement, 21, 153-174. https://doi.org/10.1111/j.1745-3984.1984.tb00227.x

[13] Marsh, H.W. (1990) A Multidimensional, Hierarchical Self-Concept: Theoretical and Empirical Justification. Educational Psychology Review, 2, 77-171. https://doi.org/10.1007/BF01322177

[14] Shavelson, R.J., Hubner, J.J. and Stanton, G.C. (1976) Self-Concept: Validation of Construct Interpretations. Review of Educational Research, 46, 407-441. https://doi.org/10.3102/00346543046003407

[15] James, W. (1890/1892) Psychologie: The Briefer Course. Henry Holt \& Co., New York.

[16] Bariaud, F. (2006) Le Self-Perception Profile for Adolescents (SPPA) de S. Harter. L'Orientation Scolaire et Professionnelle, 35, 282-295. http://osp.revues.org/1118 https://doi.org/10.4000/osp.1118

[17] Harter, S. (1985) The Self-Perception Profile for Children. Unpublished Manual, University of Denver, Denver.

[18] Harter, S. (1988) The Self-Perception Profile for Adolescents. Unpublished manual, 
University of Denver, Denver.

[19] General Statistics Office (2009) The 2009 Vietnam Population and Housing Census: Major Findings. General Statistics Office, Vietnam.

http://www.gso.gov.vn/Modules/Doc Download.aspx?DocID=11532

[20] Trịnh Thị Linh (2010) Pratiques éducative parentales, estime de soi et mobilisation scolaire de l'adolescent vietnamien. La dynamique de la représentation de l'accompagnement scolaire parental, Thèse de doctorat de Psychologie Nouveau régime, Université Toulouse II.

[21] Trịnh Thị Linh (2014) Tự đánh giá bản thân-cái tôi gia đình-nhìn từ góc độ Tâm lý học xã hội, Tạp chí Tâm lý học, Số 10/2014, 65-75.

[22] Fitts, W.H. (1965) Tennessee Self-Concept Scale Manual. Counselor Recordings and Tests, Nashville.

Submit or recommend next manuscript to SCIRP and we will provide best service for you:

Accepting pre-submission inquiries through Email, Facebook, LinkedIn, Twitter, etc. A wide selection of journals (inclusive of 9 subjects, more than 200 journals)

Providing 24-hour high-quality service

User-friendly online submission system

Fair and swift peer-review system

Efficient typesetting and proofreading procedure

Display of the result of downloads and visits, as well as the number of cited articles

Maximum dissemination of your research work

Submit your manuscript at: http://papersubmission.scirp.org/

Or contact jss@scirp.org 